\title{
Urinary excretion of hippuric acid and $m$ - or $p$-methylhippuric acid in the urine of persons exposed to vapours of toluene and $m$ - or $p$-xylene as a test of exposure
}

\author{
MASANA OGATA, KATSUMARO TOMOKUNI and YOHIKO TAKATSUKA \\ Department of Public Health, Okayama University Medical School, Okayama, Japan
}

\begin{abstract}
Ogata, M., Tomokuni, K., and Takatsuka, Y. (1970). Brit. J. industr. Med., 27, 43-50. Urinary excretion of hippuric acid and $m$ - or $p$-methylhippuric acid in the urine of persons exposed to vapours of toluene and $m$ - or $p$-xylene as a test of exposure. Twenty-three male volunteers were exposed in groups of four or five to toluene and $m$ - and $p$-xylene vapour for periods of 3 hours or of 7 hours with one break of an hour. Urine was collected at hourly intervals for several hours, and thereafter all urine was collected until 18 hours after the end of the exposure period, and was analysed for hippuric and methylhippuric acids. It was shown that hippuric acid was excreted equivalent to $68 \%$ of the toluene absorbed, and $m$-methylhippuric acid equivalent to $72 \%$ of the $m$-xylene absorbed. Up to hydrocarbon concentrations of $200 \mathrm{ppm}$ the total quantity of hippuric acids excreted was proportional to the total exposure (ppm $\times$ hours). In descending order of precision the following were also related to exposure: rate of excretion during the exposure period; concentrations of hippuric acid in urine corrected to constant urine density; and concentrations in urine uncorrected for density. The last could not be used to calculate exposure, but the others could be to give screening tests to show whether workmen could have been exposed to concentrations greater than the maximum allowable.

The effects of exposure on blood pressure, pulse rate, flicker value, and reaction time were measured. There were some variations which suggested that the MAC of toluene should be set higher than $200 \mathrm{ppm}$.
\end{abstract}

For the reasons given by Ogata, Tomokuni, and Takatsuka (1969), exposure to toluene and $m$ - or $p$-xylene is best estimated by determining the quantities of their metabolites, hippuric acid and $m$ - or $p$-methylhippuric acid, excreted in the urine. Using the analytical methods already described (Ogata et al., 1969) we show here how the quantities of metabolites are related to exposure, and consequently what levels of metabolites in urine correspond to the maximum allowable concentrations suggested by the American Conference of Governmental Industrial Hygienists (1967), namely 200 ppm for toluene and $100 \mathrm{ppm}$ for xylene. (Xylene is used as the commercial mixture of the three isomers called 'xylol', of which $75-80 \%$ is $m$-xylene.) Experiments were carried out on volunteers, who inhaled known concentrations of the vapours of toluene or xylene or both.

The symptoms and signs induced by exposure are also reported.

\section{Methods}

Experiments were carried out on 23 male volunteers, students at Okayama University Medical School, average age 23 years, who had had no previous contact with toluene or $m$ - or $p$-xylene. For each experiment four or five volunteers were exposed to a hydrocarbon. For exposure to toluene or xylene they remained in 
the exposure chamber either for 3 hours in the morning and for 4 hours in the afternnon with a break of an hour in between, or just for 3 hours in the morning. For exposure to mixed vapours they remained in the chamber for 3 hours in the morning only.

The vapour concentrations in the chamber were determined every half hour by gas chromatography with a flame ionization detector (Hitachi Co. Ltd., K-53) and were also checked by a Kitagawa detector every quarter of an hour. The averages of the concentrations found by gas chromatography were taken as correct. They were constant to within $\pm 8 \%$.

During the last two hours of exposure the concentrations in the air expired by the subjects were also determined by gas chromatography. From the differences between the concentration of toluene and $m$-xylene in the inspired and expired air the quantities of toluene and $m$-xylene retained by the subjects were calculated. The average minute volume respired by the subjects was 8.6 litres.

The quantity of hippuric acid which would appear in the urine if all the toluene absorbed was converted and excreted is given by:

$\mathrm{mg}$ hippuric acid excreted $=$ C.V.t.F. $\mathrm{M}_{\mathbf{H}} / \mathbf{M}_{\mathbf{T}}$,

where $\mathrm{C}=$ concentration of toluene in $\mathrm{mg} / \mathrm{litre}$, $\mathrm{V}=$ minute volume, $\mathrm{t}=$ exposure time in minutes, $F=$ fraction of toluene retained by the lungs, and $M_{\mathbf{H}}$ and $\mathbf{M}_{\mathbf{T}}$ are the MWs of hippuric acid and toluene respectively. A similar formula, obtained by substituting the MWs of methylhippuric acid and xylene for $M_{H}$ and $\mathbf{M}_{\mathbf{T}}$ in the original formula, gives the theoretical maximum excretion of methylhippuric acid after exposure to xylene.

From each subject in most experiments all the urine was collected for about a day after exposure in each experiment, and the urine was analysed for hippuric and methylhippuric acids.

The urines of subjects exposed only to toluene were analysed for hippuric acid by the paper chromatographic method of Ogata, Sugiyama, and Moriyasu (1962) in which butanol-acetic acid-water $(4: 1: 1$ by vol.) is used as the developing solvent. The urines of subjects exposed to xylene or mixed vapours were analysed by the paper chromatographic method described by Ogata et al. (1969) in which the colour was developed on the paper. (This would not now be the method of choice see Ogata et al. (1969) - but as the work was started using this method, it was decided to continue using it.)

At the beginning and the end of the exposure period the subjects' systolic and diastolic blood pressure, pulse rate, flicker value, and reaction time were measured. Flicker values were determined using the Flicker Value Apparatus, Model FL-10 (Shibata Co. Ltd), and the reaction time from eye to hand was determined by a Reaction Time Meter (Yamakoshi Co. Ltd).

\section{Results}

\section{Time course of excretion of metabolites}

Figure 1 shows the curve for the average excretion of hippuric acid after exposure to toluene. The excretion increased rapidly for the first 2 hours, levelled off during the intermission without exposure, and then rose again during the afternoon's exposure to a maximum somewhat before the time the subjects left the exposure chamber. By 18 hours later the concentrations had fallen nearly to the normal levels. Overall the curve was much as expected if curves for 3 and 4 hours' exposure were superposed with an hour between, i.e., the excretion was proportional to total exposure.

Figure 2 shows the corresponding curve for the excretion of $m$-methylhippuric acid after exposure to $m$-xylene, and closely resembles Figure 1 . The resemblances can be shown in another way. Of the total hippuric acids excreted in the exposure time +18 hours, the percentages excreted during the exposure periods were very similar throughout these experiments: $60.1 \%$ during exposure to 100 ppm of toluene, $54.6 \%$ during $200 \mathrm{ppm}$ of toluene, $54.0 \%$ during $100 \mathrm{ppm}$ of $m$-xylene, and $61.0 \%$ during $200 \mathrm{ppm}$ of $m$-xylene.

As can be seen from both Figs 1 and 2, rates of excretion ( $\mathrm{mg} / \mathrm{min}$ ) were much more reproducible than urinary concentrations $(\mathrm{mg} / \mathrm{ml})$ even after the latter had been corrected for variations in the density

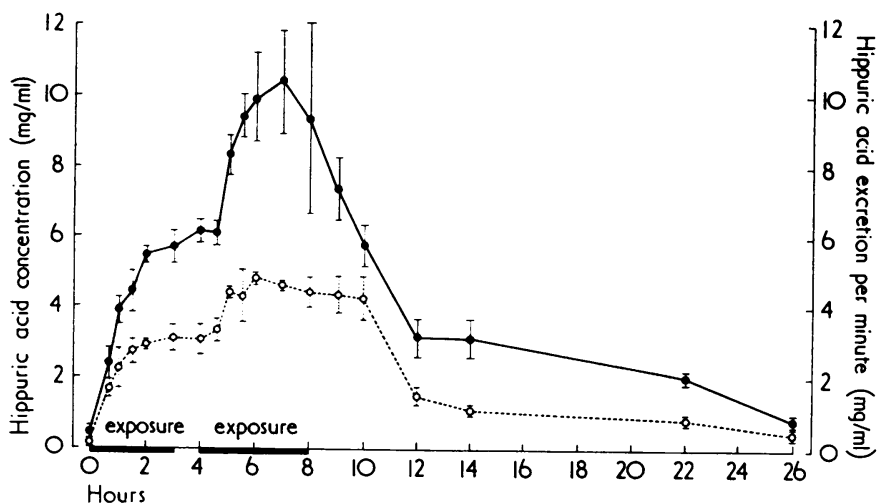

FIG. 1. Urinary concentrations and excretion rates of hippuric acid in the urine of volunteers exposed to $196 \mathrm{ppm}$ toluene for 3 hours in the morning and for 4 hours in the afternoon with one hour's break in between (mean \pm SEM): - concentration $(\mathrm{mg} / \mathrm{ml})$; o - . . - o rate $(\mathrm{mg} / \mathrm{min})$. 

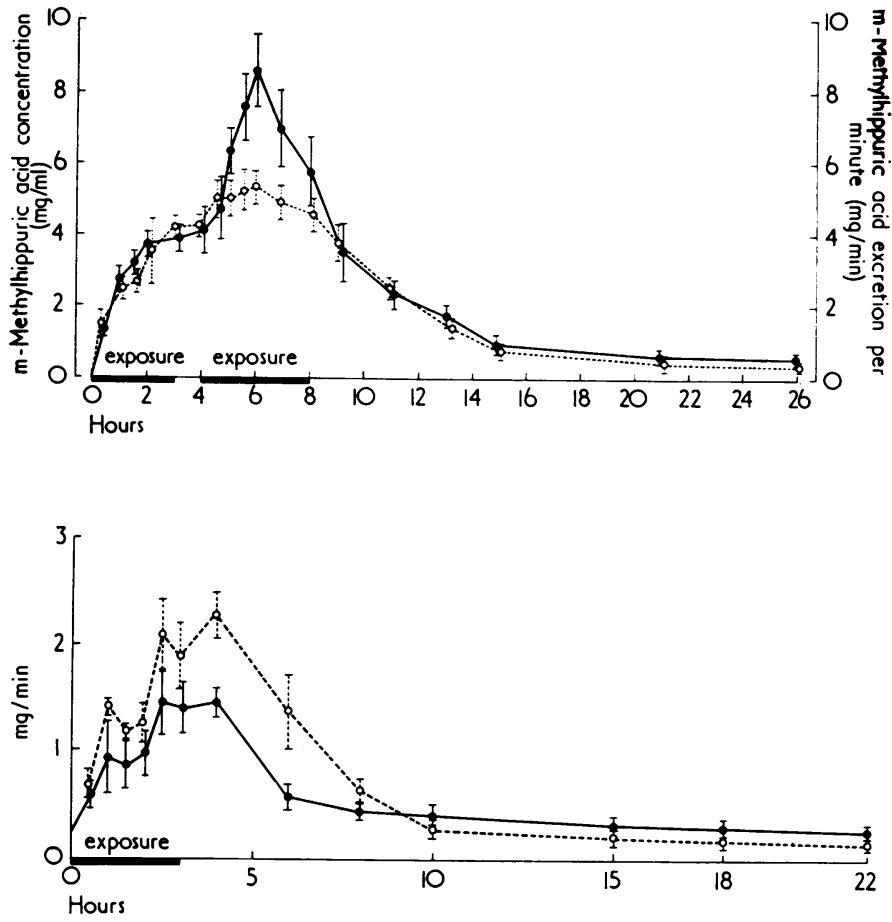

FIG. 2. Urinary concentrations and excretion rates of $m$-methylhippuric acid in the urine of volunteers exposed to $185 \mathrm{ppm} m$-xylene for 3 hours in the morning and for 4 hours in the afternoon with one hour's break in between (mean \pm SEM):

$\longrightarrow$ concentration $(\mathrm{mg} / \mathrm{ml})$; o . . . . . o rate $(\mathrm{mg} / \mathrm{min})$.
FIG. 3. Rates of excretion of hippuric acid - and $m$-methylhippuric acid $\bigcirc \ldots . . . \bigcirc$ from volunteers exposed for 3 hours to $67 \mathrm{ppm}$ toluene and $83 \mathrm{ppm} m$-xylene (means $\doteq \mathrm{SEM}$ ). of urine to density $=1 \cdot 024$. This density was close to the mean for our subjects.

Figure 3 shows the rates of excretion during and after a 3-hour exposure to a mixture of $67 \mathrm{ppm}$ of toluene and $83 \mathrm{ppm}$ of $m$-xylene. The excretion curves for hippuric and $m$-methylhippuric acids were again very similar. This similarity is illustrated by the fact that, of the total excreted, $31.5 \%$ of the hippuric acid and $30.8 \%$ of the methylhippuric acid was excreted during the 3 hours' exposure.

\section{Relationship between exposure and total metabolites excreted}

The total exposure can be measured in the units: ppm $\times$ time in hours. Figure 4 shows that when the total hippuric acids excreted in the exposure period +18 hours are plotted against the total exposures the results fall on two straight lines, i.e., excretion was proportional to exposure. The line for hippuric acid excretion is higher than that for methylhippuric acid excretion by the amount of hippuric acid excreted by the unexposed controls. Results for $p$-xylene fall on the same line as those for $m$-xylene. The fraction of the material entering the lungs which was converted to and excreted as hippuric acids was therefore very similar whichever compound, toluene, $m$-xylene or $p$-xylene or mixture of toluene and $m$-xylene, was used, and whatever the concentration in the air or the duration of exposure.

In the experiments involving exposure to a mixture of $67 \mathrm{ppm}$ of toluene and $83 \mathrm{ppm}$ of $m$-xylene described in the preceding section, the expired air from the subjects was analysed for toluene and $m$-xylene, with the results shown in Table 1 . The ratio $m$-xylene : toluene absorbed was $1 \cdot 37$, and was very close to the ratio of the quantities of the corresponding metabolites excreted, 1.46. The total metabolites excreted were equivalent to $68 \%$ of the toluene absorbed and to $72 \%$ of the $m$-xylene absorbed.

\section{Relationship between exposure and rates of excretion} of metabolites or the concentrations excreted

It is obvious from the preceding section that very precise and reproducible estimates could be made of exposure to toluene and xylene from determinations of the total hippuric acid excreted over a period continued for 18 hours after the exposure had ceased. This is not usually feasible. The results were therefore treated in the different ways illustrated in Fig. 5 to try to find other methods of estimating exposure. The urine specimens taken over the exposure periods only were sampled so as to give specimens representative of the three periods $0-3$, 4-8, and 0-8 hours after the start of exposure, and 


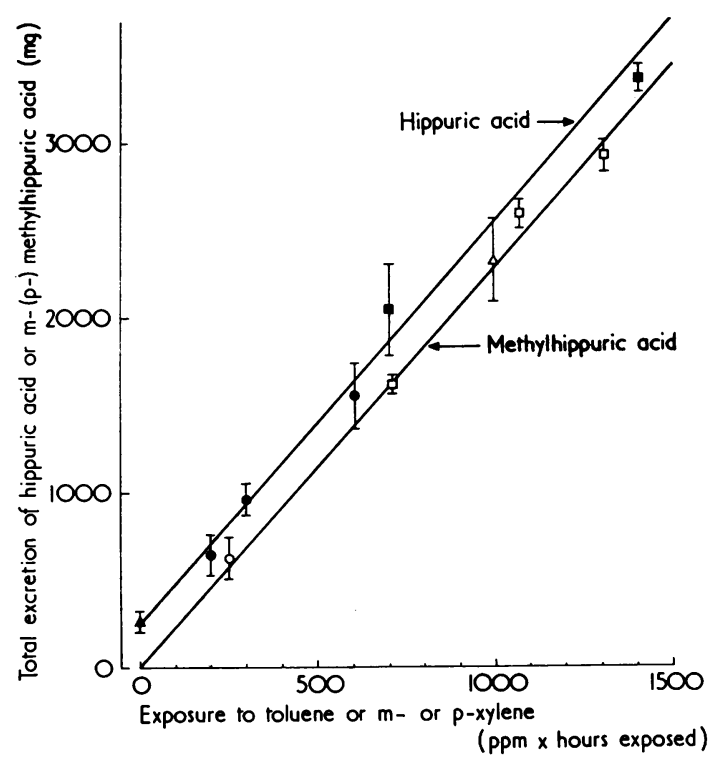

FIG. 4. Relationship between total exposure $(\mathrm{ppm} \times \mathrm{hr})$ and total excretion of urinary hippuric acid from: $\boldsymbol{\Delta}$, normal individuals; $\boldsymbol{O}$, those exposed 3 hours to toluene (for the lowest point mixed with $m$-xylene); and, $\square$, those exposed 7 hours to toluene; and of urinary methylhippuric acid from: $\bigcirc$, those exposed 3 hours to $m$-xylene; $\square$, those exposed 7 hours to $m$-xylene; and $\triangle$, those exposed 7 hours to $p$-xylene. Means \pm S.E.M.s are shown. these specimens were analysed. The results are shown in Figs $5 \mathrm{~A}, 5 \mathrm{~B}$, and $5 \mathrm{C}$ respectively. Each figure contains three curves: the dashed line represents the concentrations found; the continuous line represents the concentrations corrected to a urine density of 1.024; and the dotted line the excretion rates in milligrams per minute. In the Figures the points have been displaced a little to the left or right in most instances to avoid over-lap. The best estimates are shown in the accompanying Tables. In these Tables the values under ' 200 ppm' were obtained by extrapolation, as the concentrations within the chamber were a few per cent less.

In Fig. 5, the standard deviation (SD) and $2 \times \mathrm{SD}$ ranges are shown. As each group consisted of four or five determinations the $2 \times \mathrm{SD}$ range will contain about $90 \%$ of the expected values, i.e., about $5 \%$ of a similarly exposed population are expected to excrete less and about $5 \%$ more than the amounts corresponding to the ranges. The ranges of concentrations were considerably decreased in nearly every instance by correcting results to a urine density of $1 \cdot 024$, and consequently only concentrations corrected in this way will be considered further. The standard deviations of rates of excretion were still smaller, both absolutely and as fractions of the mean values (coefficients of variation).

Effects of exposure on physiological measurements The results of these are shown in Table 2.

Pulse rate The pulse rates of subjects exposed to $200 \mathrm{ppm}$ of toluene decreased significantly after 3

TABLE 1

Relationship between Absorption by Five VolunteErs of a Mixture of Toluene and $m$-Xylene ANd QUANTITIES OF HIPPURIC AND $m$-MethylhipPURIC ACIDS EXCRETED IN URINE

\begin{tabular}{|c|c|c|c|c|c|}
\hline \multicolumn{3}{|c|}{ Mixture to which exposed } & \multicolumn{3}{|c|}{ Inhalation } \\
\hline & \multirow{2}{*}{$\begin{array}{l}\text { Conc. } \\
\text { (ppm) }\end{array}$} & \multirow{2}{*}{$\frac{\begin{array}{c}\text { Ratio } \\
\text { m-xylene }\end{array}}{\text { toluene }}$} & \multicolumn{2}{|c|}{ Fractions of inhaled vapour } & \multirow{2}{*}{$\begin{array}{l}\text { Ratio absorbed: } \\
\frac{\text { m-xylene }}{\text { toluene }}\end{array}$} \\
\hline & & & Expired & Absorbed & \\
\hline Toluene & 67 & \multirow{2}{*}{$1 \cdot 24$} & $0 \cdot 21$ & $0 \cdot 79$ & \multirow{2}{*}{$1 \cdot 37$} \\
\hline$m$-Xylene & 83 & & 0.13 & 0.87 & \\
\hline
\end{tabular}

\begin{tabular}{|c|c|c|c|}
\hline Metabolite & $\begin{array}{l}\text { Total excreted } \\
\quad(\mathrm{mg})\end{array}$ & $\begin{array}{l}\text { Total excreted } \\
\text { minus control }\end{array}$ & $\begin{array}{c}\text { Ratio excreted: } \\
\text { methylhippuric acid } \\
\text { hippuric acid }\end{array}$ \\
\hline $\begin{array}{l}\text { Hippuric acid } \\
m \text {-Methylhippuric acid }\end{array}$ & $\begin{array}{l}643 \cdot 0 \\
636 \cdot 6\end{array}$ & $\begin{array}{l}405 \cdot 4 \\
636 \cdot 6\end{array}$ & 1.46 \\
\hline
\end{tabular}



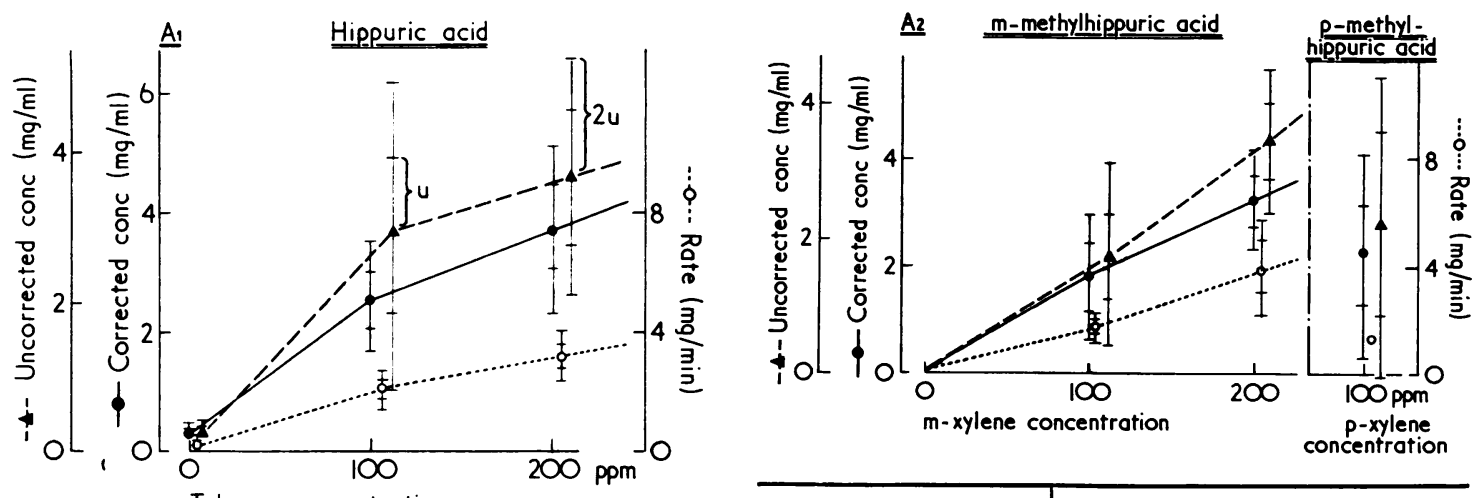

\begin{tabular}{ll|l|l|l}
\hline \multicolumn{2}{c|}{ Sampling (hr) } & \multicolumn{2}{c}{$0-3$} \\
\hline ppm & & 100 & 200 & 0 \\
\hline Uncorrected & Mean & 2.95 & 3.74 & 0.27 \\
(mg/ml) & SD & 0.83 & 0.59 & 0.10 \\
Corrected & Mean & 2.58 & 3.71 & 0.30 \\
(mg/ml) & SD & 0.40 & 0.67 & 0.10 \\
Rate & Mean & 2.09 & 3.13 & 0.19 \\
(mg/min) & SD & 0.35 & 0.36 & 0.07 \\
& B. & &
\end{tabular}

\begin{tabular}{|c|c|c|c|c|}
\hline \multicolumn{2}{|c|}{ Sampling $(h r)$} & \multicolumn{3}{|c|}{$0-3$} \\
\hline & & \multicolumn{2}{|c|}{$\mathrm{m}$-Xylene } & \multirow{2}{*}{$\frac{\text { p-Xylene }}{100}$} \\
\hline ppm & & 100 & 200 & \\
\hline $\begin{array}{l}\text { Uncorrected } \\
(\mathrm{mg} / \mathrm{ml})\end{array}$ & $\begin{array}{l}\text { Mean } \\
\text { SD }\end{array}$ & $\begin{array}{l}1 \cdot 75 \\
0.85\end{array}$ & $\begin{array}{l}3.59 \\
0.65\end{array}$ & $\begin{array}{l}2 \cdot 11 \\
1 \cdot 27\end{array}$ \\
\hline $\begin{array}{l}\text { Corrected } \\
(\mathrm{mg} / \mathrm{ml})\end{array}$ & $\begin{array}{l}\text { Mean } \\
\text { SD }\end{array}$ & $\begin{array}{l}1 \cdot 78 \\
0.61\end{array}$ & $\begin{array}{l}3 \cdot 19 \\
0.46\end{array}$ & $\begin{array}{l}2.26 \\
0.96\end{array}$ \\
\hline $\begin{array}{l}\text { Rate } \\
\text { (mg/min) }\end{array}$ & $\begin{array}{l}\text { Mean } \\
\text { SD }\end{array}$ & $\begin{array}{l}1 \cdot 69 \\
0 \cdot 29\end{array}$ & $\begin{array}{l}3 \cdot 89 \\
0.89\end{array}$ & $\begin{array}{l}1 \cdot 54 \\
0.23\end{array}$ \\
\hline
\end{tabular}
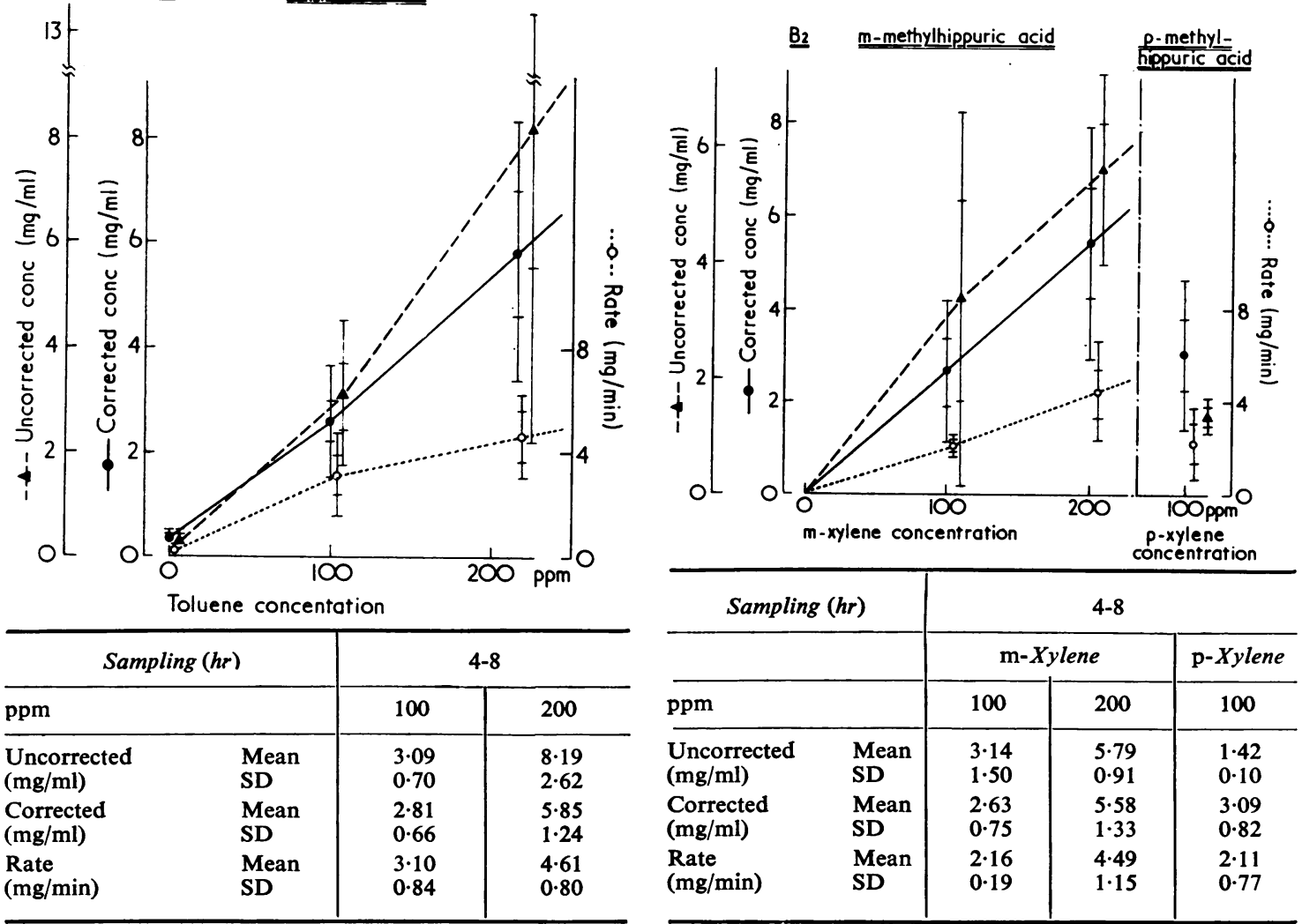

\begin{tabular}{ll|l|l}
\hline \multicolumn{2}{c|}{ Sampling $(h r)$} & \multicolumn{2}{|c}{$4-8$} \\
\hline ppm & 100 & 200 \\
\hline Uncorrected & Mean & 3.09 & 8.19 \\
(mg/ml) & SD & 0.70 & 2.62 \\
Corrected & Mean & 2.81 & 5.85 \\
(mg/ml) & SD & 0.66 & 1.24 \\
Rate & Mean & 3.10 & 4.61 \\
(mg/min) & SD & 0.84 & 0.80 \\
\hline
\end{tabular}

FIG. 5. Legend overleaf 


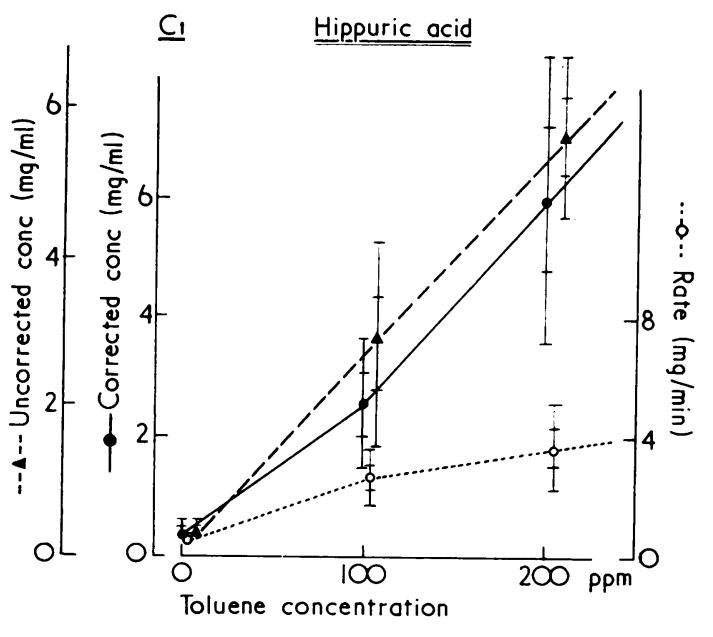

\begin{tabular}{ll|l|l}
\hline \multicolumn{2}{c|}{ Sampling $(h r)$} & \multicolumn{2}{c}{$0-8$} \\
\hline ppm & 100 & 200 \\
\hline Uncorrected & Mean & 2.81 & 5.74 \\
(mg/ml) & SD & 0.71 & 0.60 \\
Corrected & Mean & 2.55 & 5.99 \\
(mg/ml) & SD & 0.55 & 1.20 \\
Rate & Mean & 2.54 & 3.77 \\
(mg/min) & SD & 0.38 & 0.72 \\
& & & \\
\hline
\end{tabular}

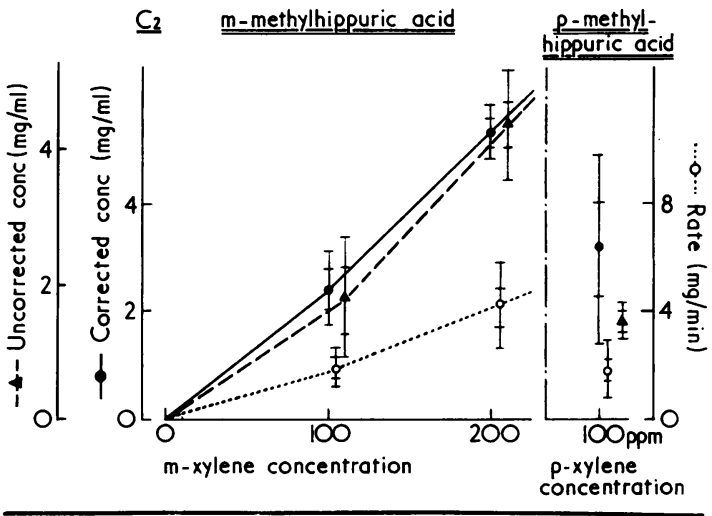

\begin{tabular}{ll|c|c|c}
\hline \multicolumn{2}{c|}{ Sampling $(h r)$} & \multicolumn{3}{c}{$0-8$} \\
\cline { 3 - 5 } & & \multicolumn{2}{c}{$\mathrm{m}$-Xylene } & $\mathrm{p}$-Xylene \\
\hline $\mathrm{ppm}$ & 100 & 200 & 100 \\
\hline Uncorrected & Mean & 1.86 & 4.56 & 1.45 \\
(mg/ml) & SD & 0.48 & 0.49 & $0 \cdot 10$ \\
Corrected & Mean & 2.39 & 5.32 & 2.50 \\
(mg/ml) & SD & 0.33 & 0.24 & 0.69 \\
Rate & Mean & 1.78 & $4 \cdot 10$ & 1.75 \\
(mg/min) & SD & 0.34 & 0.84 & 0.21 \\
& & & & \\
\hline
\end{tabular}

FIG. 5. Relationships between toluene or $m$ - or $p$-xylene concentrations in the air and concentrations and excretion rates of urinary hippuric or $m$ - or $p$-methylhippuric acids. Concentration, uncorrected, - - - A - . -; corrected to density $=1.024, \longrightarrow$; rates, $\cdots \cdots 0 \cdots$. Means, standard deviations (SD), and $2 \times$ SD are shown. All groups were exposed for 7 hours: $A_{1}, A_{2}$, urine specimens representative of the first 3 hours of expoure; $B_{1}, B_{2}$ urine specimens representative of the last 4 hours of exposure; $C_{1}, C_{2}$ urine specimens representative of the whole period of exposure.

hours' exposure. $m$-Xylene tended to decrease the pulse rate, but not significantly.

Systolic blood pressure There was an insignificant tendency for systolic blood pressure to decrease during exposure in all experiments. A decrease was found by von Oettingen, Neal, and Donahue (1942). A decrease of pulse pressure was also observed.

Diastolic blood pressure and flicker value Exposure caused no consistent changes.

Reaction time Exposure to $200 \mathrm{ppm}$ of toluene tended to prolong the reaction time.

\section{Discussion}

Our aim was to relate exposure to toluene and xylene to excretion of hippuric and methylhippuric acids in such a way that the exposure can be calculated from the amounts excreted, in order to see whether workers have been exposed to concentrations in the air higher than those allowed, i.e., the MACs, $200 \mathrm{ppm}$ for toluene and $100 \mathrm{ppm}$ for $\mathrm{m}$ - and $p$-xylene. Excretion data which can be used for this purpose are, in descending order of accuracy, total excretion during and for 18 hours after exposure; excretion rates during exposure; and concentrations in uine, corrected to a density of 1.024, during the afternoon and morning working periods. Concentrations uncorrected for urine density were not usable, as the variability was too great.

Total exposure (ppm $\times$ time) could be best estimated from the total quantities of hippuric acids excreted over 24 hours (Fig. 4). It is, however, impracticable to expect workmen to collect all their urine over a 24-hour period so that other, less reliable methods will generally have to be used.

Good estimates of total exposure could also be made from the total quantities of hippuric acids excreted during the exposure period. These are expressed in Fig. 5 as rates of excretion, i.e., total excreted $\div$ time of exposure. Again it is not always 
TABLE 2

Effects of Exposure to Toluene and Xylene on Pulse Rate, Systolic and Diastolic Blood Pressure, Flicker Value, and Reaction Time of Subjects in Exposure Chamber

\begin{tabular}{|c|c|c|c|c|c|c|c|c|c|c|c|c|c|}
\hline \multirow{3}{*}{$\begin{array}{c}\text { Items } \\
\text { examined }\end{array}$} & \multirow{3}{*}{ ppm } & \multicolumn{4}{|c|}{ Toluene } & \multicolumn{4}{|c|}{$\mathrm{m}$-Xylene } & \multicolumn{4}{|c|}{ p-Xylene } \\
\hline & & \multicolumn{2}{|c|}{$\begin{array}{c}\text { Morning } \\
\text { (hours' exposure) }\end{array}$} & \multicolumn{2}{|c|}{$\begin{array}{c}\text { Afternoon } \\
\text { (hours' exposure) }\end{array}$} & \multicolumn{2}{|c|}{$\begin{array}{c}\text { Morning } \\
\text { (hours' exposure) }\end{array}$} & \multicolumn{2}{|c|}{$\begin{array}{c}\text { Afternoon } \\
\text { (hours' exposure) }\end{array}$} & \multicolumn{2}{|c|}{$\begin{array}{c}\text { Morning } \\
\text { (hours' exposure) }\end{array}$} & \multicolumn{2}{|c|}{$\begin{array}{c}\text { Afternoon } \\
\text { (hours' exposure) }\end{array}$} \\
\hline & & 0 & 3 & 4 & 7 & 0 & 3 & 4 & 7 & 0 & 3 & 4 & 7 \\
\hline $\begin{array}{l}\text { Pulse } \\
\text { rate/min }\end{array}$ & $\begin{array}{r}200 \\
100 \\
0\end{array}$ & $\begin{array}{l}87.0 \pm 3.9 \\
82.0 \pm 19.0 \\
89.0 \pm 7.0\end{array}$ & $\begin{array}{l}69 \cdot 0 \pm 7 \cdot 8 * \\
65 \cdot 0 \pm 13 \cdot 0 \\
84 \cdot 0 \pm 6 \cdot 0\end{array}$ & $\begin{array}{c}71 \cdot 0 \pm 4 \cdot 8 \\
75 \cdot 3 \pm 15 \cdot 0 \\
-\end{array}$ & $\begin{array}{c}67 \cdot 0 \pm 8 \cdot 7 \\
69 \cdot 5 \pm 17 \cdot 0 \\
-\end{array}$ & $\begin{array}{l}79 \cdot 0 \pm 10 \cdot 0 \\
87 \cdot 0 \pm 7 \cdot 4 \\
89.0 \pm 7 \cdot 0\end{array}$ & $\mid \begin{array}{l}74 \cdot 0 \pm 6 \cdot 0 \\
84 \cdot 0 \pm 7 \cdot 4 \\
84 \cdot 0 \pm 6 \cdot 0\end{array}$ & $\begin{array}{c}76.0 \pm 6.0 \\
91.0 \pm 7.4 \\
-\end{array}$ & $\begin{array}{c}70 \cdot 0 \pm 10 \cdot 0 \\
77 \cdot 5 \pm 6 \cdot 0 \\
-\end{array}$ & $\begin{array}{c}-\overline{6} \\
84 \cdot 6 \pm 4 \cdot 1 \\
89.0 \pm 6.9\end{array}$ & $\begin{array}{l}\text { - } \\
66 \cdot 6 \pm 4 \cdot 3 \\
84 \cdot 0 \pm 6 \cdot 0\end{array}$ & $76 \cdot 2 \pm 8 \cdot 1$ & $67.0 \pm 4.8$ \\
\hline $\begin{array}{l}\text { Systolic } \\
\text { pressure } \\
(\mathrm{mmHg})\end{array}$ & $\begin{array}{r}200 \\
100 \\
0\end{array}$ & $\left|\begin{array}{l}116 \cdot 0 \pm 4 \cdot 0 \\
103 \cdot 3 \pm 11 \cdot 0 \\
114 \cdot 0 \pm 6 \cdot 0\end{array}\right|$ & $\begin{array}{r}110.0 \pm 5.0 \\
90.0 \pm 3.0 \\
110.0 \pm 11.0\end{array}$ & $\begin{array}{c}114.0 \pm 4.0 \\
97.5 \pm 11.0 \\
-\end{array}$ & $\mid \begin{array}{c}111.0 \pm 2.0 \\
97.0 \pm 1.0 \\
-\end{array}$ & $\begin{array}{l}116 \cdot 0 \pm 18 \cdot 0 \\
122 \cdot 0 \pm 14 \cdot 4 \\
114 \cdot 0 \pm 6 \cdot 0\end{array}$ & $\begin{array}{l}116 \cdot 0 \pm 11 \cdot 0 \\
117 \cdot 0 \pm 12 \cdot 7 \\
110 \cdot 0 \pm 11 \cdot 0\end{array}$ & $\mid \begin{array}{c}116.0 \pm 10.0 \\
115.0 \pm 17.8 \\
-\end{array}$ & $\mid \begin{array}{c}111 \cdot 0 \pm 14 \cdot 0 \\
113 \cdot 8 \pm 11 \cdot 1 \\
-\end{array}$ & $\begin{array}{l}-\overline{3} \text { 土 } 6 \cdot 1 \\
114 \cdot 0 \pm 6 \cdot 0\end{array}$ & $\begin{array}{c}101 \cdot 7 \pm 7 \cdot 7 \\
110 \cdot 0 \pm 11 \cdot 0\end{array}$ & $115 \cdot \overline{0} \pm 13 \cdot 2$ & $96 . \overline{0} \pm 19 \cdot 7$ \\
\hline $\begin{array}{l}\text { Diastolic } \\
\text { pressure } \\
\text { (mmHg) }\end{array}$ & $\begin{array}{r}200 \\
100 \\
0\end{array}$ & $\begin{array}{l}57 \cdot 0 \pm 11 \cdot 0 \\
57 \cdot 3 \pm 11 \cdot 0 \\
76 \cdot 0 \pm 2 \cdot 0 \\
\end{array}$ & $\begin{array}{l}70.0 \pm 6.0 \\
57.0 \pm 8.0 \\
71.0 \pm 9.0\end{array}$ & $\begin{array}{c}57.0 \pm 11.0 \\
61.0 \pm 6.0 \\
-\end{array}$ & $\begin{array}{c}71.0 \pm 11.0 \\
66.3 \pm 9.0 \\
-\end{array}$ & $\begin{array}{l}70 \cdot 0 \pm 16 \cdot 0 \\
82 \cdot 5 \pm 9 \cdot 6 \\
76 \cdot 0 \pm 2 \cdot 0\end{array}$ & $\begin{array}{l}75.0 \pm 17.0 \\
78.3 \pm 8.5 \\
71.0 \pm 9.0\end{array}$ & $\begin{array}{c}64.0 \pm 13.0 \\
78.3 \pm 14.4 \\
-\end{array}$ & $\begin{array}{c}77 \cdot 0 \pm 21 \cdot 0 \\
78 \cdot 3 \pm 17 \cdot 6 \\
-\end{array}$ & $\begin{array}{c}75 \cdot 0 \pm 5 \cdot 0 \\
76 \cdot 2 \pm 2 \cdot 0\end{array}$ & $\begin{array}{c}70 \cdot 0 \pm 91 \cdot 7 \\
71 \cdot 0 \pm 9 \cdot 0\end{array}$ & $\begin{array}{c}73 \cdot 0 \pm 12 \cdot 5 \\
-\end{array}$ & $57 \begin{array}{c}5 \pm 129 \\
-\end{array}$ \\
\hline $\begin{array}{c}\text { Flicker } \\
\text { value** } \\
(\%)\end{array}$ & $\begin{array}{r}200 \\
100 \\
0\end{array}$ & $\begin{array}{l}100 \cdot 0 \\
100 \cdot 0\end{array}$ & $\begin{array}{r}100.0 \pm 1.9 \\
89.0 \pm 14.0 \\
\end{array}$ & $\begin{array}{c}104 \cdot 3 \pm 4.9 \\
-\end{array}$ & $94 . \overline{1 \pm} 1.9$ & $\begin{array}{l}100 \cdot 0 \\
100 \cdot 0 \\
100 \cdot 0\end{array}$ & $\begin{array}{r}106.0 \pm 1.0 \\
93.5 \pm 4.2 \\
89.0 \pm 14.0 \\
\end{array}$ & $\begin{array}{c}103.0 \pm 6.0 \\
95.5 \pm 0.8 \\
-\end{array}$ & $\begin{array}{c}98.0 \pm 8.0 \\
90.7 \pm 6.3 \\
-\end{array}$ & 100.0 & 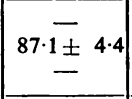 & $107 \cdot \overline{1 \pm 13.9}$ & 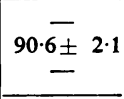 \\
\hline $\begin{array}{l}\text { Reaction } \\
\text { time } \\
\left(10^{-2} \mathrm{sec}\right)\end{array}$ & $\begin{array}{l}200 \\
100\end{array}$ & $\begin{array}{l}13.4 \pm 3.4 \\
26.0 \pm 3.3\end{array}$ & $\begin{array}{c}21 \cdot 2 \pm 0.9 \\
-\end{array}$ & $\begin{array}{l}18 \cdot 2 \pm 4 \cdot 4 \\
25 \cdot 5 \pm 1 \cdot 1\end{array}$ & $\begin{array}{l}27 \cdot 6 \pm 2.9 \\
25.9 \pm 0.9\end{array}$ & $\begin{array}{l}18 \cdot 9 \pm 2 \cdot 4 \\
15 \cdot 1 \pm 4 \cdot 3\end{array}$ & $\begin{array}{l}18 \cdot 7 \pm 0 \cdot 1 \\
16 \cdot 5 \pm 2 \cdot 7\end{array}$ & $\begin{array}{l}14 \cdot 3 \pm 3 \cdot 1 \\
17 \cdot 8 \pm 3 \cdot 8\end{array}$ & $\begin{array}{l}19 \cdot 2 \pm 2 \cdot 7 \\
17 \cdot 8 \pm 0 \cdot 9\end{array}$ & - & - & - & - \\
\hline
\end{tabular}

*Difference from controls significant at $5 \%$ level

**Percentage of value just before exposure

easy to obtain all the urine over the relevant period.

A rather less reliable approach is, however, practicable. The concentrations of hippuric acids in urine are related in a complex way to the previous exposure, and strictly the relationships between concentrations and exposure shown in Fig. 5 are only true if urine sampling is carried out in the particular way described here, and if the concentrations of toluene and xylene in air are steady. It can, however, be seen from Figs 1 to 3 that fairly steady concentrations were soon reached, and that their measurement should give an indication of the exposure during the preceding 1-2 hours.

For screening, the presence of more hippuric acid in the urine of a man than that corresponding to 2 standard deviations less than the average quantity excreted by subjects exposed to the MAC should be taken as evidence that the man may have been exposed to a concentration greater than the MAC. This will be true of about $5 \%$ of the men. (Standard deviations were calculated from results on only four or five subjects, so \pm 2 SDs should contain about $90 \%$ of the total population.) The screening quantities, as defined above, are listed in Table 3. These are given both for excretion rates and for concentrations.

The screening concentrations of hippuric acid after exposure to $200 \mathrm{ppm}$ of toluene (the MAC) was $2.37 \mathrm{mg} / \mathrm{ml}$ from $0-3$ hours or $3.37 \mathrm{mg} / \mathrm{ml}$ from 4-8 hours after the beginning of the exposure period.
TABLE 3

SCreening Levels of Hippuric ACID or MethylHIPPURIC ACID IN URINE OF WORKMEN EXPOSED TO MACS OF TOLUENE, $m$-XYLENE OR $p$-XYLENE

\begin{tabular}{l|c|cc}
\hline & \multicolumn{3}{|c}{ Exposure period (hours) } \\
\cline { 2 - 4 } & $(\mathrm{mg} / \mathrm{min})$ & \multicolumn{2}{|c}{$0-3(\mathrm{mg} / \mathrm{ml})$} \\
\hline Toluene & 2.33 & 2.37 & 3.37 \\
$m$-Xylene & 1.10 & 0.56 & 1.13 \\
$p$-Xylene & 1.33 & 0.34 & 1.45 \\
\hline
\end{tabular}

It will be noted that the screening level was higher in the afternoon than in the morning, as the concentration depended upon the total exposure over several hours preceding sampling and not just upon the exposure during the immediately preceding period. This is obvious from Figs 1 to 3, which show that the concentrations began to fall shortly after exposure ceased, but did not fall to control levels for several hours.

In considering exposure to mixed vapours, it must be remembered that the MACs for toluene and xylene are different -200 and $100 \mathrm{ppm}$ respectively so that it is necessary to estimate hippuric and methylhippuric acids separately. It is likely that the 
toxicities of toluene and xylene are additive, and that the likely total exposure should be calculated as if this were so. The fraction of the combined MAC likely to have been present can then be calculated from equations of the form:

Conc. hippuric acid

mean conc. for MAC of toluene

$$
\begin{aligned}
& +\frac{\text { Conc. methylhippuric acid }}{\text { mean conc. for MAC of xylene }} \\
& =\text { fraction of combined MAC }
\end{aligned}
$$

Concentrations of excreted acids in urine can be found in the Tables accompanying Figure 5. For instance, for urine taken in the afternoon the equation would be:

Conc. hippuric acid

$$
5 \cdot 85 \mathrm{mg} / \mathrm{ml}
$$

$$
+\frac{\text { Conc. methylhippuric acid }}{2 \cdot 63 \mathrm{mg} / \mathrm{ml}}=\text { fraction }
$$

Values of the fraction greater than 1 would indicate that the subject had probably been exposed to a total concentration greater than the combined MAC. Screening levels could be calculated similarly by substituting the screening concentrations from Table 3 in the equation instead of the mean values.

In the preceding discussion we have taken $200 \mathrm{ppm}$ of toluene as an allowable concentration. However, as $200 \mathrm{ppm}$ of toluene caused in our subjects a prolongation of reaction time, a decrease in pulse rate, and a decrease in systolic blood pressure, we do not consider that $200 \mathrm{ppm}$ of toluene is safe on the basis of our physiological observations.

On comparing toxicities in mice, Lazarew (1929) found the descending order of toxicity to be $p$-xylene, toluene, and $m$-xylene. This is in agreement with our observations.

We should like to thank Dr. H. Osaki, Mr. K. Hitomi, and Miss T. Hasegawa for their help and Mrs. K. Muroi for technical assistance.

\section{References}

American Conference of Governmental Industrial Hygienists. (1967). Threshold limit values for 1967, adopted at the 29th annual meeting of ACGIH, Chicago, Illinois. Industr. Hyg. Dig., 31, No. 9, pp. i-iv.

Lazarew, N. W. (1929). Uber die Giftigkeit verschiedener Kohlenwasserstoffdämpfe. Naunyn-Schmiedeberg's Arch. exp. Path. Pharmak., 143, 223-233.

Ogata, M., Sugiyama, K., and Moriyasu, H. (1962). Toluene concentration in air and urinary hippuric acid measured by paper chromatography and mass screening examination method. Acta Med. Okayama, 16, 283-292.

- Tomokuni, K., and Takatsuka, Y. (1969). Quantitative determination in urine of hippuric acid and $m$ - or $p$-methylhippuric acid, metabolites of toluene and $m$ - or $p$-xylene. Brit. $J$. industr. med., 26, 330-334.

von Oettingen, W. F., Neal, P. A., and Donahue, D. D. (1942). The toxicity and potential dangers of toluene. J. Amer. med. Ass., 118, 579-584.

Received for publication December 31, 1968 